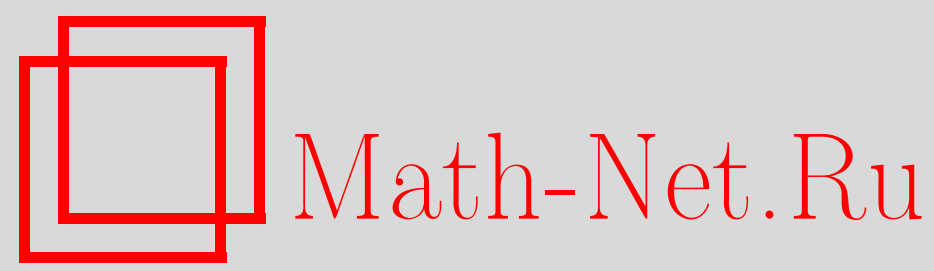

Н. И. Носкова, Структура, прочность и механизм деформации и разрушения нанокристаллических материалов, Вестн. Сам. гос. техн. ун-та. Сер. Физ.мат. науки, 2004, выпуск 27, 151-157

DOI: https://doi.org/10.14498/vsgtu293

Использование Общероссийского математического портала Math-Net.Ru подразумевает, что вы прочитали и согласны с пользовательским соглашением

http: //www. mathnet.ru/rus/agreement

Параметры загрузки:

IP: 54.80 .73 .141

26 апреля 2023 г., $17: 12: 47$ 
28. Фридель Ж. Дислокации. М.: Мир,1967. 643 с.

29. Бернер Р., Кронмюллер Г. Пластическая деформация монокристаллов. М.: Мир, 1969. 272 с.

30. Алексеев А.А., Горячев С.В., Струнин Б.М. Эволюция ансамбля скоплений дислокаций на начальной стадии пластической деформации кристаллов. // Элементарные процессы пластической деформации кристаллов. Киев. Наукова думка, 1978. С. 52-53.

31. Рыбин В.В., Орлов А.Н. Подвижность дислокаций в кристаллах с высоким Пайерлсовским рельефом. // ФТТ. 1969. Т. 12. Вып. 12. С. 3605-3608.

32. Никитенко В.И. Подвижность дислокаций в потенциальном рельефе Пайерлса. // Динамика дислокаций. Киев. Наукова думка, 1975. С. 7-26.

33. Ерофеева С.А., Осиньян Ю.А. Подвижность дислокаций в кристаллах $\mathrm{A}^{3} \mathrm{~B}^{5} / /$ Динамика дислокаций. Киев. Наукова думка, 1975. С. 26-30.

34. Иденбом В.А., Орлов А.Н. Современные представления о подвижности дислокаций. // Динамика дислокаций. Харьков. ФТИНТ АН УССР. 1968. С. 5-25.

35. Котрелля Л.Х. Дислокации и пластическое течение в кристаллах. М.: Металлургиздат, 1958. 267 с.

36. Третьяков. Термодинамика ферритов. Л.: Химия, 1967. 304 с.

37. Митлина Л.А., Молчанов В.В., Посыпайко Э.Д., Михайлов В.А. Движение дислокаций в пленках феррошпинелей. Куйбышев. 1985. 7 с. Деп. в ВИНИТИ 30.01.85. № 894- 85.

38. Надгорный Э.М. Динамические свойства изолированных дислокаций. // Несовершенства кристаллического строения и мартенситные превращения. М.: Наука, 1972. С. 151-175.

39. Johnston W.G., Gilmann J.J. Dislocation multiplication in lithium fluoride crystals. // J. Appl. Phys. 1964. Vol. 31 . №4. P. 632-634.

УДК 539.21:539.415

\section{Н.И. Носкова}

\section{СТРУКТУРА, ПРОЧНОСТЬ И МЕХАНИЗМ ДЕФОРМАЦИИ И РАЗРУШЕНИЯ НАНОКРИСТАЛЛИЧЕСКИХ МАТЕРИАЛОВ}

Иследована структура и свойства нанокристаллических металлов и сплавов, полученных способами интенсивной пластической деформации и нанокристаллизации аморфных сплавов. Методами высокоразрешающей просвечивающей электронной, растровой микроскопии и "іп situ” исследованы деформация и разрушение нанокристаллических $\mathrm{Al}, \mathrm{Cu}, \mathrm{Ni}$. Mo, Ti и сплавов на основе $\mathrm{Fe}, \mathrm{Cu}, \mathrm{Al}$ и Ті. Проанализированы структурные особенности, прочность и механизмы пластической деформации и разрушения нанокристаллических материалов.

К наноструктурным материалам в настоящее время относят такие металлы и сплавы, у которых один или несколько структурных параметров (кристаллическое зерно, толщина слоя в многослойных покрытиях, диаметр трубки или жилы в многожильных композитах) имеют размер, не превышающий 100 нм. Общепринято считать, что в нанокристаллическом многофазном материале размер нанокристаллического зерна $(\leq 100$ нм) не превышает размера нанофазы. В нанокристаллическом состоянии чистые металлы и сплавы имеют повышенные твердость, предел текучести и предел прочности; магнитомягкие нанокристаллические материалы характеризуются более низким, а магнитотвердые нанокристаллические материалы более высоким значением коэрцитивной силы по сравнению с крупнозеренным состоянием. В нанокристаллическом состоянии металлы и сплавы проявляют повышенные трибологические свойства, имеют низкие значения коэффициента теплопроводности и высокие значения коэффициента зернограничной диффузии [1]. В то же время остаются нерешенными вопросы об особенностях и температурной стабильности дефектов, о физической природе изменения свойств, о механизмах тех или других физических процессов (пластической деформации, разрушения, диффузии, теплопроводности) нанокристаллических материалов. В данной работе будут проанализированы структурные особенности, уровень прочности, механизмы пластической деформации и разрушения ряда нанокристаллических материалов.

Структурные особенности нанокристаллических металлов и сплавов. В настоящее время прямыми методами высокоразрешающей просвечивающей электронной микроскопии (HRTEM) показано, что нанокристаллические чистые металлы $\mathrm{Au}, \mathrm{Ag}, \mathrm{Pd}, \mathrm{Ni}, \mathrm{Cu}, \mathrm{Fe}[1,2]$, полученные методом сублимации с последующим прессованием наноразмерного порошка, имеют достаточно совершенную в объеме нанозерен кристаллическую решетку с единичными дислокациями и, наряду с обычными границами поликристаллов, имеют искаженные зернограничные прослойки с присутствием на границах нанозерен аморфной фазы. При использовании способа сублимации для получения нанокристаллических металлов в последних могут возник- 
нуть внутренние упругие напряжения. Кроме этого, нанозерна имеют повышенную поверхностную энергию, а материал - избыточный свободный объем

Нанокристаллические чистые металлы $\mathrm{Cu}, \mathrm{Ni}, \mathrm{Pd}, \mathrm{Fe}, \mathrm{Mo}, \mathrm{W}$ [1,3-5], полученные методом интенсивной пластической деформации (ИПД), имеют в объеме нанозерна высокий уровень упругих искажений, увеличивающийся по мере приближения к границе нанозерна, и на границах нанозерен из-за высокой плотности дислокаций - неравновесное состояние. Спектр разориентаций нанозерен по сравнению со спектром разориентаций зерен обычного поликристалла смещен в сторону малых углов.

Структура нанозерен и зернограничных областей нанокристаллических многофазных сплавов, полученных кристаллизацией аморфного состояния, исследованы в ряде работ [1,4-7]. Результаты этих исследований позволяют полагать, что кристаллическая решетка нанозерна (нанофазы) может быть бездефектной, с дефектами и упруго напряженной. Бездефектными, повидимому, являются только нанофазы наименьшего размера (4-6 нм). Что касается межзеренных границ нанофаз, то они могут иметь различное строение - квазиаморфное, сильно искаженное кристаллическое или с дислокациями несоответствия - и представлять собой переходный слой с иным химическим составом.

На основании исследований фазового состава нанокристаллических многофазных сплавов получено [1,5,7], что аморфный сплав после нанокристаллизации, как правило, имеет основную фазу, определяющую физические свойства сплава, и фазы, проявляющие себя как метастабильные или сопутствующие. Исследования кристаллизации аморфного сплава $\mathrm{Fe}_{73,5} \mathrm{Cu}_{1} \mathrm{Nb}_{3} \mathrm{Si}_{13,5} \mathrm{~B}_{9}$ непосредственно в колонне электронного микроскопа (in situ) подтвердили, что наряду со стабильными фазами в процессе кристаллизации возникают метастабильные фазы $[1,7]$.

Прочность и пластичность нанокристаллических материалов. Прочностные свойства нанокристаллических материалов определяются, в основном, размером нанозерна $d$ и состоянием границ нанозерен. Так, при уменьшении размера $d$ с 1500 нм до 5 нм в чистых металлах и сплавах микротвердость $H$ может увеличиться от 2-х до 6-ти раз $[1,8,9]$ (табл. 1, табл. 2). Предел текучести $\sigma_{s}$ и предел прочности $\sigma_{b}$ нанокристаллических металлов и сплавов также возрастают по сравнению с крупнозеренным состоянием. При этом низкотемпературная пластичность $\delta$ уменьшается (табл. 1, табл. 2). Для нанокристаллических материалов наблюдается скоростная и температурная зависимости прочностных и пластических характеристик. Эта зависимость в некоторых случаях проявляется иначе, чем для крупнокристаллических материалов. Так для меди с размером зерна 20 нм и для никеля с размером зерна 70 нм предел текучести возрастает при увеличении скорости растяжения с $10^{-3} \mathrm{c}^{-1}$ до $10^{-1} \mathrm{c}^{-1}$ при комнатной температуре. Коэффициент упрочнения может уменьшиться при этом, а пластичность - возрастать.

Зависимость Холла-Петча $\sigma_{s}=\sigma_{o}+k d^{0,5}$, где $\sigma_{o}$-решеточное трение, $k=f(G, b), G$-модуль сдвига и $b$ - значение вектора Бюргерса, для нанокристаллов может быть выражена через микротвердость $H=f\left(k d^{-0.5}\right)$. Многочисленные опыты по проверке этой зависимости в нанокристаллических чистых металлах и сплавах $[1,9,12]$ показали, что она выполняется не во всем интервале значений $d=(2-100 \mathrm{нм})$ и существенно зависит от способа получения нанокристаллической структуры ( табл. 1 , табл.2).

Отклонение от выполнения закона Холла-Петча при значениях размера нанозерен 10-6 нм исследователи предположительно связывают с изменением механизма деформации в нанокристаллических материалах. По-видимому, такое предположение имеет право на существование, поскольку известно, что напряжение, необходимое для начала работы источника дислокаций, в нанозерне очень высокое, например, для никеля с размером зерен (размером дислокационного источника) 140 нм напряжение начала работы источника дислокаций равно 870 МПа при значении модуля сдвига никеля 95 МПа. Механические свойства некоторых нанокристаллических многофазных сплавов представлены в табл. 2. Как видно из табл. 2, сплав в аморфном состоянии может иметь предел прочности и выше (FeCuNbSiB), и ниже (CoFeSiB) [1,9-12] значения предела прочности нанокристаллического (нанофазного) сплава. Что касается пластичности, то при переходе в нанокристаллическое состояние пластичность возрастает, если процесс сопровождается релаксацией внутренних упругих напряжений. Большой эффект ( $\delta$ увеличивается с 2 до $80 \%$ для сплава $\mathrm{PdCuSi}$ ) достигается, если кристаллизацию проводить в условиях ползучести $[1,11,12]$, когда возникает наиболее мелкое нанозерно (4-10 нм) и идут релаксационные процессы.

Механизм пластической деформации нанокристаллических материалов. Результаты исследования деформации методом “in situ” $[10,11,13]$ показывают, что деформация растяжением нанокристаллического никеля с размером зерна $30-70$ нм $[1,13]$ реализуется как за счет дис- 
локационного скольжения (рис.1, $a$ ), так и за счет разворота нанозерен (рис.1, б) В более крупных зернах возникают дислокационные скопления у границ зерен. В мелких нанозернах дислокации неподвижны, и нанозерна испытывают разворот, что, как правило, сопровождается увеличением плотности зернограничных дислокаций и возникновением деформационной полосы по границам нескольких нанозерен.

Т а б л и ц а 1

Микротвердость $(H)$, предел текучести $\left(\sigma_{s}\right)$, предел прочности $\left(\sigma_{\theta}\right)$ нанокристаллических чистых металлов с разным размером зерен $(d)[1,9,12]$

\begin{tabular}{|c|c|c|c|c|c|c|}
\hline Металл & $\begin{array}{c}\text { Изменение } \\
\text { (от и до) } \\
d, \text { нм }\end{array}$ & $\begin{array}{c}\text { Изменение } \\
\text { (от и до) } \\
\text { Н, ГПа }\end{array}$ & $\begin{array}{c}\text { Изменение } \\
\text { (от и до) } \\
\sigma_{s}, \text { МПа }\end{array}$ & $\begin{array}{c}\text { Изменение } \\
\text { (от и до) } \\
\sigma_{b}, \text { МПа }\end{array}$ & $\begin{array}{c}\text { Изменение } \\
\text { (от и до) } \\
\delta, \%\end{array}$ & $\begin{array}{c}\text { Способ } \\
\text { получения. }\end{array}$ \\
\hline $\mathrm{Al}$ & $1500-200$ & $0.3-1.2$ & $13-26$ & $42-176$ & $20-2$ & $* * *$ \\
\hline $\mathrm{Ti}$ & $50000-40$ & $0.8-6.7$ & $275-980$ & $420-1310$ & $29-5$ & $* * *$ \\
\hline $\mathrm{Pd}$ & $1500-5$ & $1-3$ & $50-249$ & $75-270$ & - & $*$ \\
\hline $\mathrm{Cu}$ & $1500-5$ & $0.5-2$ & - & - & - & $*$ \\
\hline $\mathrm{Cu}$ & $50000-50$ & $0.4-1$ & - & - & - & $*$ \\
\hline $\mathrm{Cu}$ & $50-6$ & $0.8-2.5$ & - & - & - & $*$ \\
\hline $\mathrm{Ag}$ & $1500-100$ & $0.3-0.3$ & - & - & - & $*$ \\
\hline $\mathrm{Fe}$ & $1500-10$ & $2-10.5$ & & & & $*$ \\
\hline $\mathrm{Ni}$ & $1500-15$ & $1.5-6.2$ & $205-940$ & $300-1040$ & $40-25$ & $*$ \\
\hline $\mathrm{Ni}$ & $10000-16$ & $0.15-0.7$ & - & - & - & $* *$ \\
\hline $\mathrm{Se}$ & $50-10$ & $3-10$ & - & - & - & $* *$ \\
\hline $\mathrm{Cu}$ & $200-70$ & $1.0-1.4$ & - & - & - & $* * *$ \\
\hline $\mathrm{Cu}$ & $80-10$ & $0.9-2.1$ & $60-365$ & $120-650$ & $60-30$ & $* * *$ \\
\hline $\mathrm{Fe}$ & $100000-80$ & $1.8-4.5$ & $375-1010$ & $480-1100$ & $25-15$ & $* * *$ \\
\hline Mo & $500-50$ & $1.0-6.0$ & - & - & - & $* * *$ \\
\hline $\mathrm{W}$ & $200-40$ & $3.0-6.2$ & - & - & - & $* * *$ \\
\hline $\mathrm{Cr}$ & $1500-70$ & - & $313-780$ & $485-960$ & - & $* * *$ \\
\hline
\end{tabular}

*- сублимация, **- механоактивация , ***- ИПД
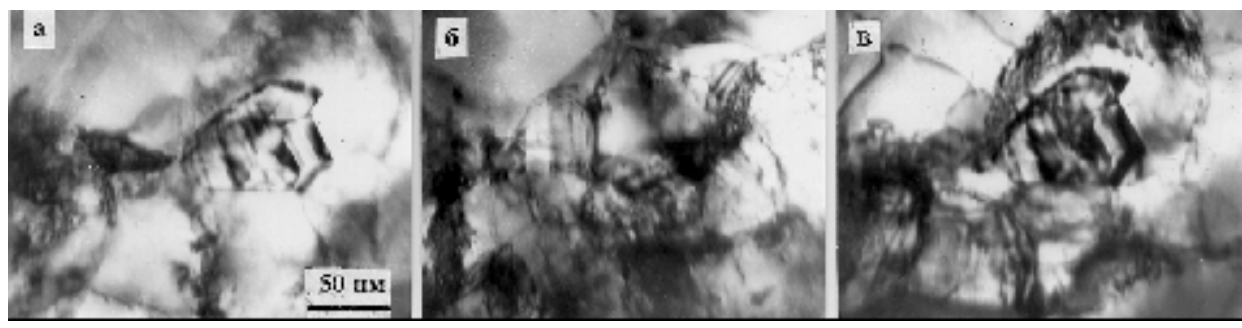

$a$

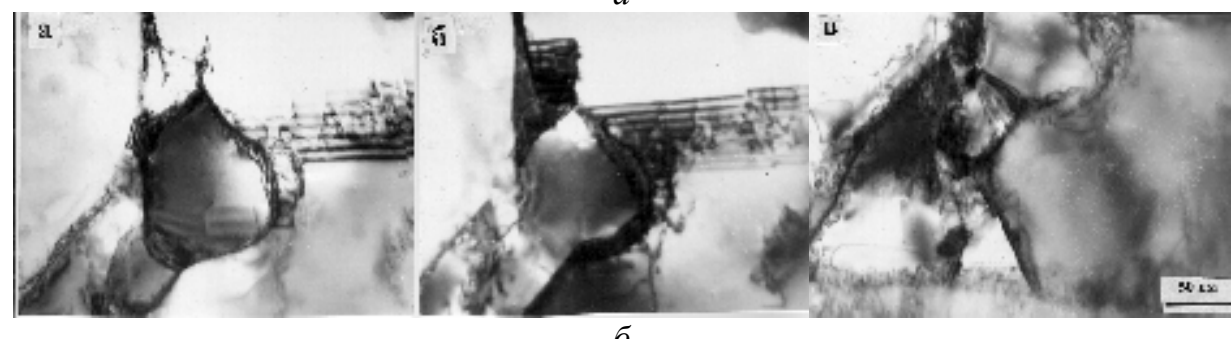

$\sigma$

Р и с. 1. Электронно-микроскопические снимки структуры нанокристаллического никеля (а- $d \leq 70 \mathrm{Hм}$; б- $d \leq 30 \mathrm{Hм})$, деформированного до разрушения в колонне электронного микроскопа (in situ): а- $\Delta \varepsilon=0.15$; б- $\Delta \varepsilon=0.35$; в- $\Delta \varepsilon=0.95$ мкм. Ось растяжения совпадает с горизонтальной осью снимка

Деформация нанокристаллической меди с размером зерна 30 нм (рис.2) реализуется, главным образом, за счет разворота зерен относительно друг друга $[1,10]$. Было определено, что при этом они разворачиваются относительно друг друга на углы от 0.5 до $30^{0}$ при увеличении степени деформации от нуля до разрыва. Вызывают разворот нанозерен, повидимому, внутренние напряжения, которые накапливаются и концентрируются в тройных стыках нанозерен, а после разворота нанозерен - перераспределяются и частично уменьшаются. Дислокации внутри зерен нанокристаллической меди в процессе деформирования остаются неподвижными. В то же время дефектность границ нанозерен существенно возрастает, границы нанозерен «уширя- 
ются», что указывает на активные деформационные процессы, идущие по границам нанозерен. Разворот нанозерен сопровождается, наиболее вероятно, возникновением несплошности по границам зерен. Перед разрушением на границах нанозерен накапливаются микротрещины и микропоры, которые объединяясь, приводят к разрушению.

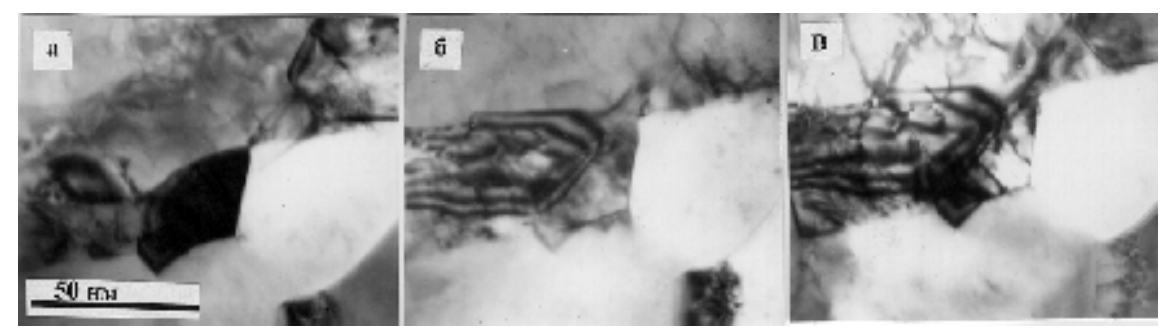

Р и с. 2 Электронно-микроскопические снимки структуры нанокристаллической меди $(d=30 \mathrm{Hм})$, продеформированной до разрушения в колонне электронного микроскопа (in situ): а- $\Delta \varepsilon=0.15$; б- $\Delta \varepsilon=0.35$; в- $\Delta \varepsilon=0.95$ мкм

Т а б л и ц а 2

Размер нанозерна $(d)$, микротвердость $(H)$, предел текучести $\left(\sigma_{s}\right)$, предел прочности $\left(\sigma_{B}\right)$, и относительное удлинение $(\delta)$ сплавов в различных структурных состояниях. $[1,9,11,12]$

\begin{tabular}{|c|c|c|c|c|c|c|}
\hline Сплав & $\begin{array}{c}\text { Изменение } \\
\text { (от и до) } \\
d, \text { нм }\end{array}$ & $\begin{array}{c}\text { Измене- } \\
\text { ние } \\
\text { (от и до) } \\
\text { Н, ГПа. }\end{array}$ & $\begin{array}{c}\text { Изменение } \\
\text { (от и до) } \\
\sigma_{\mathrm{s}}, \mathrm{MПа}\end{array}$ & $\begin{array}{c}\text { Изменение } \\
\text { (от и до) } \\
\sigma_{B}, \text { МПа }\end{array}$ & $\begin{array}{c}\text { Изменен } \\
\text { (от и до) } \\
\delta, \%\end{array}$ & $\begin{array}{c}\text { Способ } \\
\text { получе- } \\
\text { ния }\end{array}$ \\
\hline Ст.3 & $100000-80$ & - & $220-980$ & $435-1005$ & $25-8$ & $* * *$ \\
\hline BT-6 & $120000-40$ & - & $950-1080$ & $1050-1350$ & $9-7$ & $-\ll-$ \\
\hline TiAlNb & $25-10$ & $5.5-3.5$ & - & - & - & $* * * *$ \\
\hline $\mathrm{FeCuSiB}$ & $100-25$ & $8-10$ & - & - & - & $-\ll-$ \\
\hline FeSiB & $100-25$ & $6,2-11,8$ & - & $701-1150$ & - & $-\ll-$ \\
\hline$-\ll-$ & $100-25$ & $8,8-13,5$ & - & - & - & $-\ll-$ \\
\hline$-\ll-$ & $25-8$ & $13,5-6,0$ & - & - & - & $-\ll-$ \\
\hline$-\ll-$ & $\mathrm{AMC}$ & 9.4 & - & - & - & \\
\hline $\mathrm{FeCuNbSiB}$ & $200-6$ & $6,0-15,0$ & $140-2180$ & $140-2280$ & $0-0.8$ & $-\ll-$ \\
\hline$-\ll-$ & AMC & 13.6 & 2000 & 2100 & 1.8 & \\
\hline $\mathrm{FeCSi}$ & $500-25$ & - & $3480-3860$ & - & - & $-\ll-$ \\
\hline FeMoSiB & $200-10$ & $6,1-10,0$ & - & - & - & $-\ll-$ \\
\hline CoFeSiB & $100-25$ & $10,5-13,0$ & $945-1880$ & $950-2100$ & $0-2.6$ & $-\ll-$ \\
\hline$-\ll-$ & $25-8$ & $13,0-9,0$ & - & - & - & $-\ll-$ \\
\hline$-\ll-$ & AMC & 11.0 & - & 1180 & 0 & \\
\hline $\mathrm{PdCuSi}$ & $100-10$ & $4,0-7,5$ & $60-310$ & $140-550$ & 4.3 & $-\ll-$ \\
\hline$-\ll-$ & $10-4$ & $7,5-2,8$ & $310-350$ & $550-710$ & $4.3-30$ & $-\ll-$ \\
\hline$-\ll-$ & AMC & 4.6 & - & 820 & 0 & \\
\hline TiAl & $625-25$ & $3,0-12,0$ & - & - & - & $* *$ \\
\hline$-\ll-$ & $25-12$ & $12,0-6,5$ & - & - & - & $-\ll-$ \\
\hline $\mathrm{Nb}_{3} \mathrm{Sn}$ & $100-6$ & $8,0-9,0$ & - & - & - & $-\ll-$ \\
\hline $\mathrm{NbAl}_{3}$ & $100-20$ & $3,8-7,0$ & - & - & - & $-\ll-$ \\
\hline$-\ll-$ & $20-9$ & $7,0-5,7$ & - & - & - & $-\ll-$ \\
\hline $\mathrm{Al}-1,5 \% \mathrm{Mg}$ & $150-16$ & $0,4-1,6$ & - & - & - & $* * *$ \\
\hline AlMgLiZr & $500-20$ & - & - & $490-680$ & - & \\
\hline TiN & 40 & 21,0 & - & - & - & $-\ll-$ \\
\hline Y12A & $2000-20$ & $4.0-12.0$ & - & - & - & $-\ll-$ \\
\hline $12 \times 25 \mathrm{~T}$ & $2000-50$ & $1.8-6.5$ & - & - & - & $-\ll-$ \\
\hline AlNiCeFe & $2000-80$ & - & - & $120-1560$ & - & $-\ll-$ \\
\hline $\mathrm{Al}_{2} \mathrm{O}_{3}$ & 70 & 22,0 & - & 3750 & - & $*$ \\
\hline $\mathrm{Ni}_{3} \mathrm{Al}$ & $1000-60$ & - & - & $780-3000$ & - & \\
\hline $\mathrm{ZrO}_{2}$ & 150 & 6,4 & - & - & - & $-\ll-$ \\
\hline $\mathrm{TiO}_{2}$ & 10 & 17,0 & - & - & - & $-\ll-$ \\
\hline $\mathrm{SiN}$ & 400 & 18.0 & - & - & - & $-\ll$ \\
\hline TiN & $82-30$ & $10.7-25.0$ & - & - & - & $-\ll-$ \\
\hline $\mathrm{ZrN}$ & $140-20$ & $6.5-19.8$ & - & - & - & $-\ll-$ \\
\hline
\end{tabular}


В нанокристаллическом титане при деформации растяжением также наблюдается активизация ротационных мод деформации и появление деформационных сдвиговых полос по границам нескольких нанозерен. Наряду с этим, в нанокристаллическом титане с увеличением степени деформации возникают в нанозернах микродвойники одинаковой ориентации $[1,12]$, что, повидимому, связано с активизацией ротационных мод деформации, вызывающих увеличение пластичности материала.

На рис. 3 a,б, в,2, приведены электронно-микроскопические снимки одного и того же места микроструктуры нанокристаллического сплава $\mathrm{Al}+1 \% \mathrm{Hf}$ после последовательно увеличивающейся степени деформации растяжением ( метод “in situ"). Из рис.3 видно, что деформация реализуется дислокационно-ротационным механизмом деформации (с увеличением степени деформации происходит разворот нанозерен и увеличивается плотность зернограничных дислокаций). На границе нанозерен присутствуют частицы фазы, размер которых не более 10 нм. С развитием деформации частицы фаз, по-видимому, затрудняют выход из границы дислокаций, с одной стороны, а, с другой - частицы фаз, взаимодействуя с зернограничными дислокациями, испытывают «растворение». Одновременно с этим в объеме нанозерен наблюдается возникновение дисперсных фаз, размером не более 1 нм, что, несомненно, вызывает упрочнение объема нанозерен.

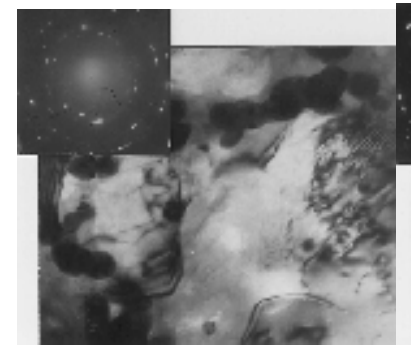

$a$

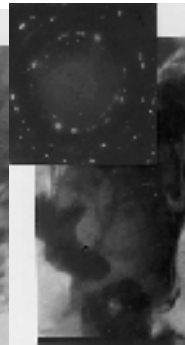

$\sigma$

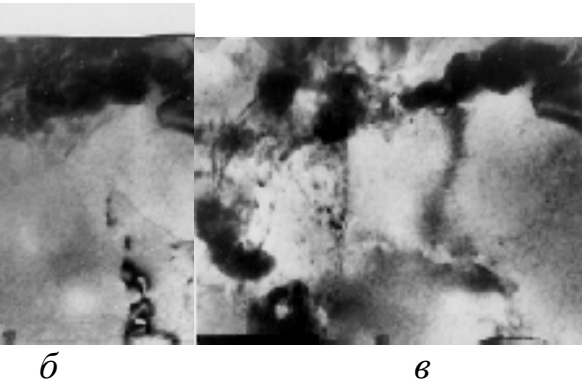

B

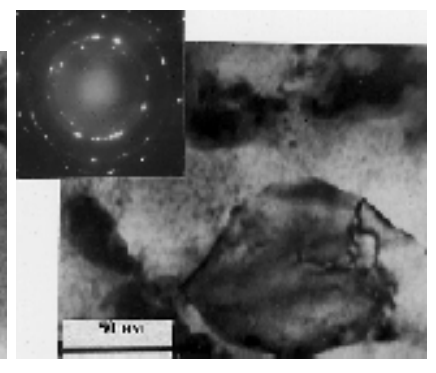

2

Р и с. 3. Электронно-микроскопические последовательные снимки одного и того же места деформируемого в колонне электронного микроскопа нанокристаллического ( $d=60$ нм) сплава $\mathrm{Al}+1 \% \mathrm{Hf}$ : а- $\Delta \varepsilon=0,38 ;$ б- $\Delta \varepsilon=0,48$; в- $\Delta \varepsilon=0,60 ; г-\Delta \varepsilon=2,00$ мкм.

Результаты исследования деформации растяжением нанокристаллического сплава $\mathrm{Fe}_{73.5} \mathrm{Cu}_{1} \mathrm{Nb}_{3} \mathrm{Si}_{13.5} \mathrm{~B}_{9}$ [1,11-13] непосредственно в колонне электронного микроскопа показывают, что процесс деформации реализуется ротациями цепочки нанозерен и развивается вдоль границ нанозерен, образуя в направлении действия максимальных сдвиговых напряжений узкие деформационные полосы.

На рис. 4 приведены характерные снимки поверхности разрушения нанокристаллических молибдена (позиция «1»), меди (позиция «3») и сплавов (позиции «2» и «4»). И в том, и другом случаях разрушение происходит по границам нанозерен, с той разницей, что в случае нанокристаллической меди развитие микротрещины происходит по границе нескольких одинаково ориентированных нанозерен, чем обеспечивается более высокая низкотемпературная пластичность нанокристаллической меди $[1,9,14]$ ( рис.4 б, в позиция «3»).

Остановимся на особенностях деформационного разрушения полученной наноструктуры, на примере сплава $\mathrm{Al}+1 \% \mathrm{Hf}$. Процесс развития
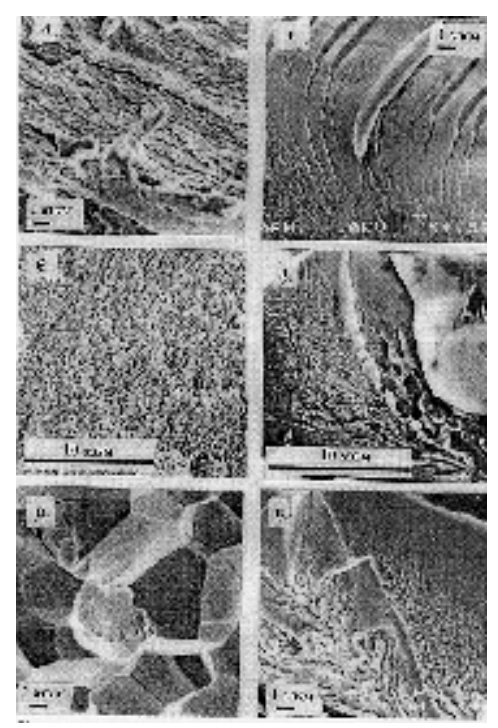

1

2
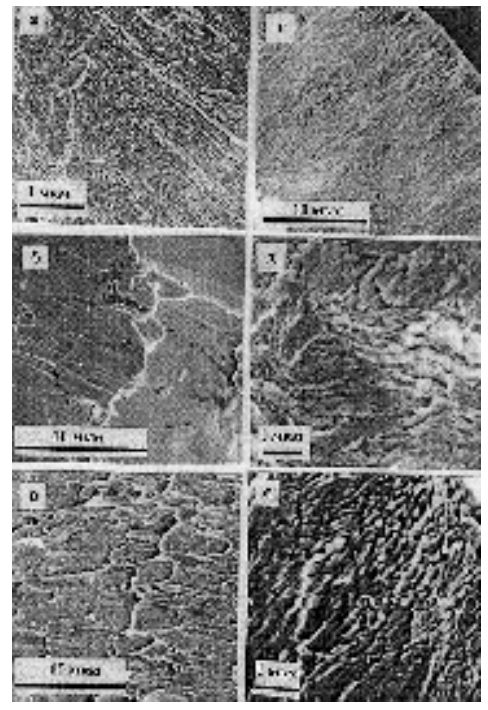

3
4

$\mathrm{P}$ и с. 4. Электронно-микроскопические снимки поверхности разрушения: 1- Мо; 2- сплава $\mathrm{Fe}_{73.5} \mathrm{Cu}_{1} \mathrm{Nb}_{3} \mathrm{Si}_{13.5} \mathrm{~B}_{9}$ ( $a$ - $d=50$, б- $d=60, \varepsilon-d=900 ; 2-d=6, \partial-d=10, e-d=10 \mathrm{нм}) ; 3-\mathrm{Cu}$ и 4 - сплава $\mathrm{Pd}_{81} \mathrm{Cu}_{7} \mathrm{Si}_{12}(a-d=20, \sigma-d=20$, $в-d=40 ; z-d=4$, $\partial-d=10, e-d=40$ нм). 
деформации и разрушения наблюдался непосредственно в колонне электронного микроскопа методом “in situ”. На рис.5, a и на схеме рис.5, 6 показаны последовательные стадии развития микротрещины в нанокристаллическом сплаве $\mathrm{Al}+1 \% \mathrm{Hf}$. Отметим основную характерную особенность развития деформации и разрушения. Как уже было отмечено выше, деформация развивается по границам нанозерен и реализуется дислокационными и ротационными модами деформации. Ротационные моды деформации на границах нанозерен возникают несплошности, которые формируют микропору. С увеличением степени деформации дислокационные моды деформации вызывают перенапряжения в тройном стыке нанозерен, в котором зарождается предвестник микротрещины (один или несколько), который, как правило, развивается перед острым концом микротрещины (рис.5 a, 6 позиции «1» и «2»). Дислокационные моды деформации в тройном стыке нанозерен перед острым концом микротрещины продолжают вызывать перенапряжения и приводят к слиянию предвестника микротрещины с микропорой (рис.5 а,б, позиция «3»).

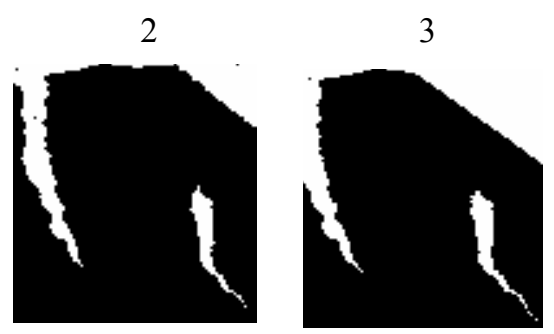

$a$

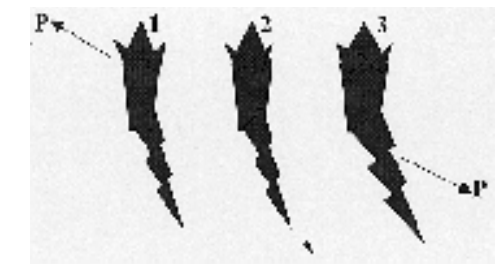

$\sigma$

Р и с. 5. Электронно-микроскопические снимки развития (a) и схемы (б) микротрещины в сплаве $\mathrm{Al}+1 \% \mathrm{Hf}$ при исследовании деформации методом "in situ".

Цифры: $1-\Delta \varepsilon=2.0$ мкм; $2-\Delta \varepsilon=2.6$ мкм; $3-\Delta \varepsilon=2.9$ мкм

Что касается поверхностей хрупкого разрушения, приведенных на снимках рис. $4 \mathrm{a}$ и рис.4г для позиций «1», «2», «3» и «4», то в этих случаях в материале обнаружены высокие внутренние упругие напряжения, которые подавляют эффект размера зерна.

Итак,уменьшение размера зерна до десятков нанометров в нанокристаллических металлах и сплавах сопровождается ростом их прочности и твердости. На основании результатов исследования деформации ГЦК, ОЦК и ГПУ нанокристаллических материалов методом "in situ" можно, по-видимому, считать справедливым для всех исследованных нанокристаллических структур следующее положение: с уменьшением размера нанозерна в нанокристаллическом материале при деформации растяжением возникают ротационные моды, которые приводят к смене дислокационного механизма деформации на дислокационноротационный, а вследствие своей кооперативности приводят к развитию по границам нанозерен мезоскопических деформационных сдвигов. Развитие ротационных мод деформации в нанокристаллических материалов приводит к появлению ротационной пластичности в виде образования мезоскопических сдвигов по границам зерен и к возникновению микропор и микротрещин. Последние приводят к разрушению материала.

\section{БИБЛИОГРАФИЧЕСКИЙ СПИСОК}

1. Носкова Н.И., Мулюков Р.Р. Субмикрокристаллические и нанокристаллические металлы и сплавы. Екатеринбург: УрО РАН. 2003. 279 c.

2. Birringer R., Gleiter H. Nanocrystalline Materials.// Encyclopedia of materials science and engineering, Suppl. 1988. V. 1. P. 339-349.

3. Valiev R.Z. and Musalimov R.Sh. High-Resolution Transmission Electron Microscopy of Nanocrystalline Materials. // The Physics of Metals and Metallography. 1994. V.78. № 6. P. 666-670.

4. Носкова Н.И., Пономарева Е.Г., Мышляев М.М. Строение нанофаз и границ раздела в нанокристаллическом многофазном сплаве $\mathrm{Fe}_{73} \mathrm{Ni}_{0,5} \mathrm{Cu}_{1} \mathrm{Nb}_{3} \mathrm{Si}_{13}{ }_{5} \mathrm{~B}_{9}$ и в нанокристаллической меди. // ФММ. 1997. Т. 83. №5. С. 73-79.

5. Носкова Н.И., Сериков В.В., Глазер А.А., Клейнерман Н.М., Потапов А.П. Электронно-микроскопическое и мессбауровское исследование структуры и строения сплава $\mathrm{Fe}_{73,5} \mathrm{Cu}_{1} \mathrm{Nb}_{3} \mathrm{Si}_{13,5} \mathrm{~B}_{9}$ в нанокристаллическом состоянии. // ФММ. 1992. № 7. С. 80-86.

6. Surinach S., Otero A., Baro M.D., Tonejc A.M., Bagovic D. Nanocrystallization of amorphous FeCuNbSiB based alloys. // NanoStructured materials. 1995. V.6. № 1-4. P. 461-464.

7. Noskova N.I.,Ponomareva E.G Structure transformations in amorphous Fe, Co, and Pd based alloys at transitionin a nanocrystalline state.// NanoStructured Materials. 1997. V. 9. P. 379-382.

8. Valiev R., Korznikov A., and Mulyukov R. Structure and properties of ultrafine-grained materials produced by severe plastic deformation.// Materials Science and Engineering. 1993. V. A168. P. 141-148.

9. Носкова Н.И. Структура, прочность и пластичность аморфных и нанокристаллических материалов. // ФММ, 1998. V. 86. № 2. С. 179-190.

10. Noskova N.I., Volkova E.I. In situ Study of Deformation of Nanocrystalline Copper.// The Physics of Metals and Metallography. 2001. V. 91. No.6. P. 629-635. 
11. Noskova N.I., Volkova E.G. In situ Investigations of Deformation in Nanocrystalline $\mathrm{Fe}_{73.5} \mathrm{Cu}_{1} \mathrm{Nb}_{3} \mathrm{Si}_{13.5} \mathrm{~B}_{9}$ Alloy // Physics of Metals and Metallography. 2001. V. 92. №.4. P. 421-425.

12. Noskova N.I. Structural Features, and Mechanisms of Deformation of Nanocrystalline Materials // J. Phys. Metals and Metallography. 2002. Suppl. V.94. P.S119-S130.

13. Носкова Н.И. Образование мезоскопического деформационного сдвига в нанокристаллических материалах.// Вопросы материаловедения. 2002. №1(29). С. 309-313.

14. Noskova N.I., Korznikov A.V.Plasticity and Fracture of Nanostructured Materials // J. Phys. Metals and Metallography. 2002. Suppl. V.94. P.S24-S29.

Работа выполнена при финансовой поддержке грантов Р Урал № 01-03-96436 и Р Урал № 02-02-96413

УДК 539.21

В.А. Путилин, А.М. Штеренберг ОПРЕДЕЛЕНИЕ КОЭФФИЦИЕНТА МАССОПЕРЕНОСА МЕДИ В НИКЕЛЕ
ПРИ КОРОТКОИМПУЛЬСОМ ЛАЗЕРНОМ ВОЗДЕЙСТВИИ

Рассчитан коэффициент массопереноса меди в никеле при интенсивном лазерном облучении.

Изучение структурных изменений, происходящих в кристаллических твердых телах при прохождении по ним лазерно-индуцированных ударных волн, имеет фундаментальное значение для физики твердого тела. [1,2] Однако высокоскоростные методики исследования, позволяющие фиксировать изменения структуры материалов в процессе ударного деформирования, еще весьма несовершенны. В связи с этим возникает необходимость теоретического анализа процессов, происходящих в металлах, подвергнутых облучению короткими импульсами лазера. Для решения этой задачи большое практическое и теоретическое значение имеет определение кинетических параметров, в том числе коэффициента массопереноса.

Экспериментально исследовался массоперенос меди в никеле $[3,4]$. Образцы из технически чистого никеля после предварительной полировки и отжига в вакууме покрывались слоем меди толщиной $~ 1$ мкм посредством вакуумного напыления. После этого их со стороны слоя меди подвергали воздействию моноимпульсов рубинового лазера с модулированной добротностью. Плотность мощности поглощенного излучения составляла $10^{9}-10^{10} \mathrm{BT} / \mathrm{cm}^{2}$, а длительность импульса - 30 нс. При этом давление в лазерно-индуцированных ударных волнах составило 20 ГПа. Скорость нагружения оценивалась как $\sim 10^{7} \mathrm{c}^{-1}$.

После облучения образцы разрезались по диаметру пятна для исследования приповерхностных слоев в зоне воздействия. С целью исключения возможного шаржирования поверхности микрошлифа частицами меди в процессе механического полирования проводилась дополнительная химическая полировка поверхности микрошлифа.

Был осуществлен количественный микрорентгеноспектральный анализ распределения меди в никеле по глубине облученной зоны на микроанализаторе «Суперпроб-739». В образцах, после лазерного воздействия, была выявлена зона твердого раствора меди в никеле. В распределении меди наблюдается четко выраженный максимум на глубине около 80 мкм от поверхности, а полная глубина проникновения атомов меди была порядка 300 мкм.

Наличие концентрационного пика в распределении меди в никеле указывает на то, что перенос вещества осуществляется непосредственно фронтом лазерно-индуцированной ударной волны. Приближенный расчет показывает, что за время лазерного импульса ( $\tau=30$ нс) фронт ударной волны (скорость $\cup>6 \cdot 10^{3} \mathrm{~m} / \mathrm{c}$ ) переместится на расстояние $\ell>180$ мкм. Глубина залегания концентрационного пика меди в никеле имеет тот же порядок величины.

Оценка коэффициента массопереноса по формуле

$$
D=\frac{z^{2}}{4 t}
$$

где $\mathrm{z}$ - максимальная глубина проникновения меди в никель, $t$ - время пробегания по толщине образца лазерно-индуцированной ударной волны ( $t \sim 1$ мкс), показывает, что он имеет аномально высокое значение $\left(D \approx 0,023 \mathrm{~m}^{2} / \mathrm{c}\right)$. Можно предположить, что при определенных скоростях 